Original Article

\title{
Tearfilm immunoglobulin E (IgE) level in vernal keratoconjunctivitis by ELISA
}

\author{
Pokharel S ${ }^{1}$, Shah DN², Joshi SN ${ }^{3}$, Choudhary $\mathbf{M}^{4}$ \\ ${ }^{1}$ Lecturer, Ophthalmology Department, Kathmandu Medical College, Sinamangal, ${ }^{2}$ Professor, ${ }^{3}$ Associate Professor, \\ ${ }^{4}$ Lecturer, Ophthalmology Department, Institute of Medicine, Maharajgunj, Nepal.
}

\begin{abstract}
Background: Vernal keratoconjunctivitis (VKC) is recurrent chronic allergic conjunctivitis occurring in the prepubertal age-group with secondary involvement of the cornea and is self-limiting in character. The disease is prevalent worldwide but it shows predominance in the areas with dry and warm climate including the South Asia. VKC represents about $3 \%$ of the serious ophthalmic disease in some parts of the world where the prevalence is rate is high.Type I hypersensitivity reaction which is IgE-dependent and type IV hypersensitivity reaction have been implicated for the pathogenesis VKC.

Objective: To determine level of immunoglobulin E ( $\operatorname{IgE})$ in the tear film of patients with Vernal Keratoconjunctivitis (VKC) attending outpatient department of BP Koirala Lions Centre for Ophthalmic Studies (BPKLCOS).

Materials and methods: Thirty-four VKC patients and thirty-four controls were included in this study. Tear samples were collected using micro- capillary glass tube method and tear IgE levels were measured using an enzyme - linked immunosorbent assay (ELISA).

Results: There was high concentration of tear IgE level in VKC $(95.09 \mathrm{IU} / \mathrm{ml})$ than in controls $(1.63 \mathrm{IU} / \mathrm{ml})$ though the difference was not statistically significant $(\mathrm{p}=0.16)$. No statistically significant difference was observed in male and female gender within VKC group and when compared with control group (in male group, $\mathrm{p}=0.21$ and in female group, $\mathrm{p}=0.26$ ). There was no statistically significant difference observed in tear IgE level in different age groups within VKC group and when compared with control group $(\mathrm{p}=0.30)$. The result did not show any significant difference in tear $\operatorname{IgE}$ level with respect to the duration of the disease $(\mathrm{p}=0.23)$. There was no statistically significant difference in tear IgE level with different episodes of VKC $(\mathrm{p}=0.69)$. No statistically significant difference of IgE concentration in tear was seen among different types of VKC $(p=0.53)$ and grades of tarsal and limbal papillae $(p=0.72)$.
\end{abstract}

Conclusion: There was high concentration of tear IgE level observed in VKC.

Key words: Vernal keratoconjunctivitis, Tearfilm, IgE level, Type I hypersensitivity reaction, Type IV hupersensitivity reaction.

$\mathrm{T}$ ype I hypersensitivity reaction which is IgEdependent and type IV hypersensitivity reaction have been implicated for the pathogenesis of Vernal

Keratoconjunctivitis (VKC) $)^{1,2,3}$. However, IgEdependent hypersensitivity reaction has been observed as the important factor for the pathogenesis. IgE sensitizes cells like mast cells and basophils, resulting in degranulation and release of vasoactive amines which are responsible for clinical manifestations of $\mathrm{VKC}$.

In $\mathrm{VKC}$, tear IgE level is significantly high. In a study by Nomura $\mathrm{K}$ and Takamura E, tear IgE concentration was increased significantly in the VKC (322.2+/- 45ng/ $\mathrm{ml}=134.25 \mathrm{IU} / \mathrm{ml})$, SAC $(194.7+/-21.7 \mathrm{ng} / \mathrm{ml})$ and PAC $(134.8+/-23.1 \mathrm{ng} / \mathrm{ml})$ than in controls $(52.1+/-9.7$ $\mathrm{ng} / \mathrm{ml}=21.71 \mathrm{IU} / \mathrm{ml})(\mathrm{p}=0.1)^{4}$.
In another study by Mathea R Allansmith, Hahn GS and Simon MA, the mean tear IgE concentration was high in VKC $(130 \mathrm{ng} / \mathrm{ml})$ than in controls $(61 \mathrm{ng} / \mathrm{ml})$ though the difference was not statistically significant $(\mathrm{p}=>0.05$ $<0.2)^{5}$. (1 IU=2.4 ng)

Although there are less number of studies carried out to determine tear $\operatorname{IgE}$ concentrations, $\operatorname{IgE}$ both total and specific are usually the only evidence to support the diagnosis of $\mathrm{VKC}$.

\footnotetext{
Correspondence

Dr. Suprada Pokharel, Lecturer

Kathmandu Medical College Teaching Hospital,

Sinamangal, Kathmandu

E-mail: supranp@yahoo.com
} 
This study has been conducted to evaluate the level of tear IgE in the cases of VKC in Nepalese population. No study has been undertaken in our country, regarding immunoglobulin E (IgE) level in VKC. The tear IgE level determined by this study in VKC and in normal subjects may be helpful in the diagnosis of some of the cases of VKC with atypical presentations in the people of Nepal. Thus helping timely management of those cases and preventing blinding complications like corneal opacity, astigmatism and keratoconus. This report may also be helpful to form a base-line study in future study as well.

\section{Materials and methods}

The study was carried out in the outpatient department of BPKLCOS from $1^{\text {st }}$ March $2003-15^{\text {th }}$ August 2004. It was a hospital- based case control study.

Cases of $\mathrm{VKC}$, diagnosed on the basis of history and clinical findings; and control group were collected from the outpatient department.

Informed verbal consent was taken from all cases and control group in adults and from parents in cases of children before enlisting them in the study. Variables of the study included age, sex, level of tear film IgE in cases, control and duration of VKC, episodes of $\mathrm{VKC}$, clinical type of $\mathrm{VKC}$, sizes of papillae and $\mathrm{IgE}$ concentration.

Detailed history of all cases and control group was taken. All selected cases and controls were subjected to general systemic examination and detailed ocular examination to rule out other allergic diseases and ocular diseases.

Inclusion Criteria of the cases and controls were: Cases, which match diagnostic criteria of VKC, were included. Control group were individuals with quiet and normal external eye, quiet anterior or posterior segment and with no history of asthma or systemic allergy or worm infestation or systemic illnesses or history of trauma or ocular or other surgery or no history of drug intake. Diagnostic criteria for VKC included in this study were: involvement of eyes, itching, scanty yellowish white tenacious discharge, tarsal papillae or limbal elevation and Trantas' dots.

Tear sample was collected from the cases and control group selected, with the help of glass capillary tube from the lower fornices of both eyes without any ocular manipulation. The amount of tear sample collected was 40 micro litres in amount in each subject. The capillary tube with the sample was sealed with China clay in both ends and was refrigerated at $2-8^{\circ} \mathrm{C}$ till analysis. The sample was subjected to ELISA test by standardised procedure. The sensitivity of this test is such that the minimum detectable IgE concentration by this assay is estimated to be $5.0 \mathrm{IU} / \mathrm{ml}$. The optical density of the test was read at $450 \mathrm{~nm}$ with a microtiter plate reader within 15 minutes.

The average absorbance values (A450) were calculated for each set of reference standards, control and samples. A standard curve was constructed by plotting the mean absorbance obtained from each reference standard against its concentration in IU/ml on linear graph papers with absorbance values on the vertical or Y-axis and concentration on the horizontal or X-axis. Using mean absorbance value for each sample, the corresponding concentration of $\mathrm{IgE}$ in $\mathrm{IU} / \mathrm{ml}$ was determined from the standard curve.

Test kits were refrigerated at $2-8^{0} \mathrm{C}$ temperatures. All reagents were allowed to reach room temperature (18$25^{\circ} \mathrm{C}$ ) before use. At least three readings were taken from microtiter plate reader and the mean of the readings were subjected for analysis. Readings were taken by the same individual throughout the study period.

Data were entered in SPSS program and analysis was done using standardised t-test and Pearson-Chi-square statistical tests.

\section{Results}

The total number of cases and control group included in the study was 68, 34 in VKC group and 34 control group. The age of the patients and controls ranged from 2 yrs old to 26 yrs old. The maximum number of cases $(35.3 \%)$ was in age group 6-10 yrs old. There were 26 male cases $(76.5 \%), 26$ male controls, 8 female cases $(23.5 \%)$ and 8 female controls.

Out of the total, $41.2 \%$ of cases were observed in the group with more than three episodes of VKC. A total of $26.5 \%$ had persistent group with disease present throughout the whole year. 3 episodes of VKC was seen in $2.9 \%, 11.8 \%$ had 2 episodes and $17.6 \%$ had one episode only.

A history of $\mathrm{VKC}$ for more than 24 months was given by $32.4 \%$ of cases. Regarding the duration, $26.5 \%$ had the disease since 0-6 months, $23.5 \%$ had since 7 12 months and $17.6 \%$ had history of the disease since 19-24 months.

A tear IgE level 0-5 IU/ml was noted in $47.1 \%$ of $\mathrm{VKC}$ cases group had whereas $97.1 \%$ of controls had $0-5 \mathrm{IU} /$ $\mathrm{ml}$ tear IgE level. One VKC case had tear IgE level of 2 207.9IU/ml.

In control group, only one subject was in 20-25 IU/ml range with IgE level $23 \mathrm{IU} / \mathrm{ml}$. This particular subject had a family history of asthma in mother. There was no other illness in this case. The minimum IgE level 
detected in our study was $0.05 \mathrm{IU} / \mathrm{ml}$ in $\mathrm{VKC}$ and 0.029 $\mathrm{IU} / \mathrm{ml}$ in control group.

When mean tear IgE level in VKC and control group was compared a notable difference was observed but this difference was not statistically significant $(p=0.16)$. However, when IgE level 2207.9 IU/ml was excluded from the data, mean IgE concentration in VKC (31.07 $\mathrm{IU} / \mathrm{ml}$ ) when compared with control group (1.63 IU/ $\mathrm{ml})$, statistically significant difference was observed $(\mathrm{p}=0.04)$

Though mean IgE level in both VKC and control revealed high tear level in male gender when compared with females, this did not show statistically significant difference in both cases and controls within each group ( $p=0.67$ in VKC and $p=0.63$ in control group) and when compared between control and VKC groups (in male group, $\mathrm{p}=0.211$ and in female group, $\mathrm{p}=0.265$ ).

There was no statistically significant difference observed with IgE level in different age groups within
VKC group and when compared with control groups $(\mathrm{p}=0.309)$.

The result did not show any significant difference in IgE level with respect to the duration of the disease $(\mathrm{p}=0.23)$.

There was no statistically significant difference in tear IgE level with different episodes of VKC $(p=0.69)$.

No statistically significant difference of $\operatorname{IgE}$ concentration in tear was seen among different types of VKC $(\mathrm{p}=0.53)$ and grades of tarsal and limbal papillae $(p=0.72)$.

Tear IgE level in treated and untreated VKC showed no statistically significant difference $(\mathrm{p}=0.74)$. However, there were 32 treated cases and only two untreated cases in this study. One untreated VKC had IgE level $0.48 \mathrm{IU} /$ $\mathrm{ml}$ and another had $390 \mathrm{IU} / \mathrm{ml}$.

Table 1.1: Tear IgE level in VKC and Controls

\begin{tabular}{|c|c|c|}
\hline Tear IgE (IU/ml) & VKC No (\%) & Control No (\%) \\
\hline $0-5$ & $16(47.1 \%)$ & $33(97.1 \%)$ \\
\hline $5-10$ & $4(11.8 \%)$ & $0(0 \%)$ \\
\hline $10-15$ & $4(11.8 \%)$ & $0(0 \%)$ \\
\hline $15-20$ & $0(0 \%)$ & $1(2.9 \%)$ \\
\hline $20-25$ & $4(11.8 \%)$ & $0(0 \%)$ \\
\hline $25-30$ & $0(0 \%)$ & $0(0 \%)$ \\
\hline $30-35$ & $0(0 \%)$ & $0(0 \%)$ \\
\hline $35-40$ & $0(0 \%)$ & $0(0 \%)$ \\
\hline $40-45$ & $1(2.9 \%)$ & $0(0 \%)$ \\
\hline $50-55$ & $1(2.9 \%)$ & $0(0 \%)$ \\
\hline$>60$ & $4(11.8 \%)$ & $34(100 \%)$ \\
\hline Total & $34(100 \%)$ & \\
\hline
\end{tabular}

Table 1.2: Mean Tear IgE level in VKC and Controls

\begin{tabular}{|c|c|c|}
\hline Group & Cases/Subjects & Mean (IgE IU/mI) \\
\hline VKC & 34 & 95.09 \\
\hline Control & 34 & 1.63 \\
\hline
\end{tabular}

Table 2: Mean IgE level in different Sexes in VKC and Control group

\begin{tabular}{|l|c|c|c|c|}
\hline \multicolumn{1}{|c|}{ VKC } & $\begin{array}{c}\text { No. of Cases/ } \\
\text { Subjects }\end{array}$ & Max IgE(IU/mI) & Min IgE(IU/mI) & Mean IgE (IU/mI) \\
\hline Male & $26(76.5 \%)$ & 2207.90 & 0.05 & 110.88 \\
\hline Female & $8(23.5 \%)$ & 290.00 & 0.57 & 43.76 \\
\hline CONTROL & & & & 1.81 \\
\hline Male & $26(76.5 \%)$ & 23.10 & 0.029 & 1.04 \\
\hline Female & $8(23.5 \%)$ & 1.94 & 0.29 & \\
\hline
\end{tabular}




\section{Discussion}

It has been established by several studies carried out in different parts of the world that IgE plays a major role in manifestations of $\mathrm{VKC}$ and it is elevated in tear significantly in VKC. In study by Mathea R Allansmith, Gary S. Hahn and Meredith A Simon, tear IgE in VKC was observed as $130 \mathrm{ng} / \mathrm{ml}(54.17 \mathrm{IU} / \mathrm{ml})$ and in controls was $61 \mathrm{ng} / \mathrm{ml}(25.42 \mathrm{IU} / \mathrm{ml})^{5}$. In another study by Nomura $\mathrm{K}$ and Takamura E, tear IgE in VKC was $322.2 \mathrm{ng} / \mathrm{ml}$ $(134.25 \mathrm{IU} / \mathrm{ml})$ and in control group was $52.1 \mathrm{ng} / \mathrm{ml}$ $(21.71 \mathrm{IU} / \mathrm{ml})^{4}$. In study by Insler MS, Lim JM, Queng JT, Wanissorn C and Mcgovern JP, they found tear $\mathrm{IgE}$ level in allergic symptomatic group was $10 \mathrm{IU} / \mathrm{ml}$ and in nonallergic asymptomatic group was $2 \mathrm{IU} / \mathrm{ml}^{6}$. Similarly, in study by V Aalders-Deenstra tear IgE in VKC without atopy was $1.890 \mathrm{IU} / \mathrm{ml}$ and in controls was $0.058 \mathrm{IU} / \mathrm{ml}^{7}$. In our study, the patients with vernal keratoconjunctivitis had high concentration of tear IgE than the controls but it was not statistically significant. The concentration of tear $\operatorname{IgE}$ in our study was less in amount especially in control group $(=95 \mathrm{IU} / \mathrm{ml}$ in $\mathrm{VKC}$ and $1.63 \mathrm{IU} / \mathrm{ml}$ in control group) than observed in other studies conducted in other parts of the world. The test used in other studies was radioimmunosorbent technique. In our study, analysis was done by enzymelinked immunosorbent test. In another study, tear IgE level in normal tear was reported as $0.25-1.4 \mathrm{IU} / \mathrm{ml}^{8}$. Thus different levels of IgE have been reported in VKC and controls in different studies. But IgE level in all these studies has been higher in VKC than in controls.

In our study, there was difference when mean IgE concentration was compared between the VKC $(95.09 \mathrm{IU} / \mathrm{ml})$ and control group $(1.63 \mathrm{IU} / \mathrm{ml})$ but it was not statistically significant $(\mathrm{p}=0.162)$. This result was due to one VKC case with $2207.9 \mathrm{IU} / \mathrm{ml} \mathrm{IgE} \mathrm{level,}$ which has skewed the normal distribution of sample. Our result can be compared with results of the study titled 'Tissue, tear and serum IgE concentration in Vernal Conjunctivitis' by Mathea R Allansmith conducted in $1976^{5}$. This study showed no statistically significant tear IgE level difference $(54.17 \mathrm{IU} / \mathrm{ml})$ in $\mathrm{VKC}$ and $(25.42 \mathrm{IU} / \mathrm{ml})$ in controls. However, tear IgE level was high in VKC. But, they found statistically significant difference in serum IgE level between the two groups. However, serum IgE level was not performed in our study to compare serum IgE with this particular study. In our study, when one case of $\mathrm{VKC}$ with highest tear $\mathrm{IgE}$ level was excluded and data was analysed, mean tear IgE concentration difference in $\mathrm{VKC}(31.07 \mathrm{IU} / \mathrm{ml})$ and in controls $(1.63 \mathrm{IU} / \mathrm{ml})$ was significant statistically $(\mathrm{p}=0.04)$, indicating high $\operatorname{IgE}$ level in $\mathrm{VKC}$.

There was no significant variation found between tear IgE level in different age groups in VKC and in control group ( $\mathrm{p}=0.309)$ within each group. It has been proved that serum IgE level decreases with age ${ }^{6}$ but we could not find any proven study related to tear IgE level with aging.

No significant difference existed in IgE concentration both in $\mathrm{VKC}$ and controls when compared in male and female groups. However, tear mean IgE level, in general, was observed higher in male (in $\mathrm{VKC}=110.88 \mathrm{IU} /$ $\mathrm{ml}$ and in controls $=1.81 \mathrm{IU} / \mathrm{ml}$ ) than in female (in $\mathrm{VKC}=43.76 \mathrm{IU} / \mathrm{ml}$ and in controls $=1.04 \mathrm{IU} / \mathrm{ml}$ ) in both $\mathrm{VKC}$ and control groups. We could not find any study comparing tear IgE level in different ages and sex groups of individuals. Hence, it was not possible to compare our findings with other studies in this regard.

There was no significant difference $(p=0.23)$ detected with duration of disease and tear $\operatorname{IgE}$ concentration in this study. Study done in 1985 by V Aalders- Deenstra, PTM Kok and PLB Bruynzeel showed statistically significant $(p=<0.001)$ decline in level of $\operatorname{IgE}$ with chronicity $(>3 y$ rs $)$ of the allergic disease ${ }^{7}$.

There was no statistically significant difference in tear IgE concentration with different episodes of disease in our study $(\mathrm{p}=0.69)$.

There was no significant difference found when tear IgE concentration in different sizes of papillae was compared. In a study by Mathea R. Allansmith, Gary S. Hahn and Meredith A Simon, tear IgE level was not high in VKC with cobblestone papillae ${ }^{5}$.

Similarly, statistically no significant difference was found in tear IgE concentration in mixed and palpebral type of VKC $(p=0.53)$ though IgE level was high (14.6 $\mathrm{IU} / \mathrm{ml})$ in mixed type than in palpebral form (4.1 IU/ $\mathrm{ml})$. We could not find any study related to tear $\mathrm{IgE}$ level and type of VKC to compare with our study.

\section{Conclusion}

There was high concentration of tear IgE in VKC than in control group. Though mean tear IgE level in general was much higher $(95.09 \mathrm{IU} / \mathrm{ml})$ in $\mathrm{VKC}$ group in comparison to controls $(1.63 \mathrm{IU} / \mathrm{ml})$, it was not statistically significant when two groups were compared.

However, it can be concluded that as there was high concentration of tear IgE level observed in $\mathrm{VKC}$ than in control group, tear IgE concentration can help in diagnosis of atypical cases of VKC and in early prompt management. 


\section{Acknowledgement}

We would like to extend our sincere gratitude to Mr Chintamani Basyal and Mrs Menuka Thapa in BPKLCOS laboratory section for their patience and help for collecting tear samples for this study. We are grateful to Mr Chetnath Adhikari, TUTH, Microbiology department and to Mr Biswa Nath Sharma and $\mathrm{Mr}$ Rabindra Nepal in TUTH laboratory for their help in performing ELISA.

Our sincere thanks to Mr Praween Shrestha, Statistician, TUTH for helping us with statistical analysis.

\section{References}

1. McGill JI, Bacon A, Allergic eye disease mechanism. BJO. 1998; 82: 1203-14.

2. El- Asrar AMA, Struyf S, Al-Kharashi SA et al. Chemokines in limbal form of VKC. BJO. 2000; 84: 1360-6.

3. Fujishima H, Saito I, Takeuchi T, Tsubota K. Immunological characteristics of patients with Vernal Keratoconjunctivitis: Jpn J Ophthalmol. 2002; 46(3): 244-8.
4. Nomura K, Takamura E. Tear IgE concentrations in allergic conjunctivitis. Eye. 1998; 12 (Pt2): 296-8.

5. Allansmith MR, Hahn GS, Simon MA. Tissue, Tear and Serum IgE Concentrations in Vernal Conjunctivitis. AJO. 1976; 8:506-11.

6. Insler MS, Lim JM, Queng JT, Wanissorn C, McgovernJP. Tearand Serum IgEConcentrations by Tandem-R IgE Immunoradiometric Assay in Allergic patients. Oph. 1987; 94:945-8.

7. Aalders-Deenstra V, Kok PTM, Bruynzeel PLB. Measurement of total $\mathrm{IgE}$ antibody levels in lacrimal fluid of patients suffering from atopic and non-atopic eye disorders.Evidence for local $\mathrm{IgE}$ production in atopic eye disorders. BJO. 1985; 69:380-4.

8. Donshik PC, Ballow M. Tear immunoglobulins in giant papillary conjunctivitis induced by contact lenses. Am J Ophthalmol. 1983; 96:460. 